\title{
Doenças infecciosas
}

\section{emergentes}

do Departamento de

Epidemiologia

da Faculdade de Saúde

Pública da USP e autor de,

entre outros, Vigilância

em Saúde Pública

(Faculdade de Saúde

Pública da USP).

\section{e reemergentes}

ELISEU ALVES WALDMAN

\section{INTRODUÇÃO}

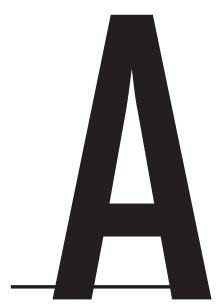

circulação contínua de agentes infecciosos entre seres humanos somente foi possível a partir do momento em que o homem passou a viver em

grupos, criando condições para assumir o papel de

reservatório de microorganismos e parasitas, tarefa em parte facilitada pelo manejo de animais e sua utilização como alimento. Com o crescimento da população humana e o desenvolvimento das diferentes civilizações, tivemos a ampliação progressiva do intercâmbio entre os continentes estabelecendo-se condições para a ampla disseminação das doenças infecciosas. Populações suscetíveis que viviam em aglomerados humanos distribuídos em pontos distantes, mas localizados em rotas de caravanas de mercadores, foram sucessivamente atingidas por novos agentes patogênicos. Exploradores e exércitos conquistadores serviram de vetores para a ampla circulação desses agentes. Esporadicamente, epidemias de doenças como a peste, a varíola e o tifo assolavam populações, muitas vezes alterando o curso da história (Satcher, 1995). 
Até o final do século XIX, as doenças infecciosas e a fome endêmica persistiam entre os principais problemas de saúde pública, sendo responsáveis por elevadas taxas de mortalidade infantil e pela baixa expectativa de vida das populações humanas. Nessa época, a falta de saneamento e as habitações insalubres constituíam ainda características das cidades; a diarréia, a varíola, a peste, a cólera e a tuberculose eram responsáveis por elevada proporção dos óbitos, mesmo em países desenvolvidos. Porém, no decorrer do século XX, a ampliação do saneamento urbano, a melhora nas condições de nutrição, a elevação do grau de escolaridade e o desenvolvimento de novas e efetivas vacinas e antibióticos propiciaram condições para expressivas melhorias nas condições de vida do homem, contribuindo para a acentuada queda na mortalidade por doenças infecciosas, especialmente na infância, e mudanças nos padrões de morbimortalidade (Beaglehole e Bonita, 1997).

Dados relativos às dez principais causas de óbitos em todo o globo, em 1998, publicados pela Organização Mundial da Saúde (OMS, 1999), mostram essas mudanças, mas também apontam expressivos diferenciais entre países industrializados e em desenvolvimento, com a convivência de novos e velhos males.

Esta lista assinala como principal causa de óbito as doenças cardiovasculares que apresentam forte associação com fatores de risco introduzidos pelo estilo de vida moderna: estresse, hábitos sedentários de vida e obesidade. Destacam-se também, nesse grupo, causas relacionadas ao comportamento humano - é o caso do câncer do aparelho respiratório fortemente associado ao hábito de fumar - e aos costumes introduzidos pela industrialização, como os acidentes de trânsito, resultado da introdução do veículo a motor, símbolo da sociedade de consumo. No entanto, mantêm sua importância representantes dos velhos males, como a tuberculose, doença tradicionalmente associada à pobreza. Por sua vez, a diarréia, apesar da melhora nas condições de saneamento e 
habitação, elevação da escolaridade e ampliação da cobertura dos serviços de saúde, manteve-se em posição relevante entre as causas de óbito, ainda que apresentando importantes diferenciais entre os continentes - quarta causa de óbito na África e vigésima segunda na Europa.

Os dados de mortalidade, relativos a 1998, apontam também a relevância de uma doença infecciosa que só recentemente atingiu a população humana, mas que rapidamente se disseminou em todo o globo, com grande impacto em saúde pública. É o caso da Aids, desconhecida até duas décadas atrás, mas que se destaca como a quarta causa de óbitos em todo o mundo, posição resultante da relevância que assumiu na África, onde é a primeira causa de morte entre adultos, dizimando populações de vários países, com forte impacto na economia e na estrutura demográfica dessas nações (Faucci, 1999).

O sarampo merece destaque como exemplo de causa de óbito que se situava até o início dos anos 90 entre as dez mais importantes em todo o globo e que por impacto da introdução de tecnologias médicas apresentou expressiva diminuição. As elevadas coberturas de vacinação alcançadas nos últimos dez anos contribuíram para a diminuição anual, em todo o mundo, de cerca de um milhão e meio de óbitos, por essa causa, em menores de 5 anos (CDC, 1998).

A expressiva queda dos óbitos por doenças infecciosas no século XX, especialmente por diarréia na infância, teve impacto importante no declínio das taxas de mortalidade geral, com reflexo na rápida elevação da expectativa de vida das populações. Se tomarmos como exemplo Inglaterra e País de Gales, verificaremos que, enquanto no século XIX a expectativa de vida elevou-se de 41 para 48 anos, no século XX esse aumento foi de 48 para 77 anos, um incremento de aproximadamente $60 \%$. Porém, essa trajetória favorável, de queda da mortalidade e elevação da expectativa de vida, não tem evitado elevadas taxas de doenças evitáveis e de mortes prematuras em boa parte do Terceiro Mundo (Beaglehole e Bonita, 1997; Powles, 1992).
A análise da tendência das doenças infecciosas em termos de morbidade deve ser feita com maior cautela, pois essa informação, mesmo para períodos mais recentes, é menos precisa do que as de mortalidade; além disso, é disponível somente para pequena parcela de países. No entanto, os dados sugerem que a morbidade acompanhou, grosso modo, a tendência da mortalidade ainda que observando menor velocidade e intensidade. Dessa forma, a partir da década de 1920, as doenças infecciosas foram progressivamente sendo superadas pelas doenças cardiovasculares, neoplasias e pela violência, tendência que se consolida após a Segunda Guerra Mundial. Essa mudança ocorreu inicialmente nos países industrializados, sendo seguidos pelas regiões em desenvolvimento, num ritmo mais lento e de forma não-homogênea (Bobadilla et al., 1993; Frenk et al., 1989).

A trajetória das doenças infecciosas, no século XX, apresentou certo sinergismo com o processo de transformação da estrutura demográfica - transição demográfica - e com a mudança dos padrões de morbimortalidade - transição epidemiológica - verificados em praticamente todos os continentes. Os principais fatores que caracterizaram a transição demográfica foram, num primeiro momento, a queda da mortalidade, seguida pela diminuição da fecundidade, aumento da expectativa de vida e, como decorrência, envelhecimento da população. Por sua vez, a transição epidemiológica caracterizouse pela diminuição expressiva da mortalidade infantil, pelo aumento da importância das doenças crônico-degenerativas e pela elevação da morbimortalidade decorrente da violência (Bobadilla et al., 1993; Frenk et al., 1989 ).

A tendência amplamente favorável das doenças infecciosas no século XX, com o controle de várias delas, inclusive de algumas que constituíram flagelos no passado, permitiu que muitos antevissem o desaparecimento desse grupo de doenças, como problema relevante em saúde pública, à medida que as populações, dos diferentes continentes, atingissem níveis mais eleva- 
dos de desenvolvimento social e econômico. Isso porque as doenças infecciosas eram entendidas como quase exclusivamente associadas à pobreza, à falta de saneamento e ao baixo nível de escolaridade da população. No entanto, a reversão dessa tendência a partir dos anos 80 , principal, mas não exclusivamente, como impacto da epidemia da síndrome da imunodeficência adquirida, apontou o equívoco dessa projeção (Armelagos, 1998).

\section{DOENCAS EMERGENTES E REEMERGENTES}

As transformações sociais e econômicas ocorridas após a Segunda Guerra Mundial, assim como o rápido desenvolvimento da ciência e tecnologia, influenciaram em boa parte do globo mudanças expressivas no estilo de vida e nas relações entre pessoas e nações, induzindo, por conseqüência, alterações significativas no próprio perfil das doenças infecciosas, que passaram a ser reconhecidas como condicionadas por um conjunto muito mais complexo de fatores determinantes.

Tais fatores ligam-se intimamente aos modelos de desenvolvimento econômico, às políticas de industrialização e a suas principais conseqüências, entre elas: o rápido processo de urbanização, as alterações ambientais nas cidades e no campo, as migrações e o aumento do intercâmbio internacional, que assumiu o papel de "vetor cultural" na disseminação das doenças infecciosas. Desses modelos de desenvolvimento econômico decorrem também a forma de incorporação das novas tecnologias médicas, a ampliação do consumo de alimentos industrializados e também, em vários países, a desestruturação dos serviços de saúde pública (Altekruse et al., 1997; Fidler, 1996; Morse e Hughes, 1996).

Essa nova realidade acelerou o processo de disseminação de microorganismos e parasitas e modificou sua interação com o homem, de forma mais rápida do que anteriormente, criando condições para a emergência e difusão de novas doenças infecciosas, para a modificação do comportamento de doenças já conhecidas e o ressurgimento de doenças consideradas, por equívoco, erradicadas. Como resultado, tivemos a partir do início dos anos 90 o retorno das doenças infecciosas à agenda de prioridades em saúde pública, mesmo nos países desenvolvidos (Morse, 1995; CDC, 1994).

Diante da necessidade de uma abordagem mais abrangente para compreendermos o seu comportamento nessa nova realidade, surgiu a partir do início dos anos 90 o conceito de doenças infecciosas emergentes e reemergentes, definidas como: “aquelas só recentemente identificadas na população humana ou já existentes, mas que rapidamente aumentaram sua incidência e ampliaram sua distribuição geográfica" (Satcher, 1995).

Na realidade, essa definição é suficientemente ampla para incluir qualquer doença infecciosa de relevância. Numa publicação sobre as mais destacadas doenças infecciosas emergentes ou reemergentes dos anos 90 estão citadas o hantavírus, a febre de Lassa, o dengue, a cólera, a coqueluche e a febre amarela, portanto, vemos lado a lado novos e velhos problemas de saúde pública (CDC, 1994).

Vale salientar que a adoção dessa denominação-doenças infecciosas emergentes - para aquelas que apresentam relevância em saúde pública tem também alguma relação com a preocupação demonstrada pelas grandes potências, também a partir dos anos 90, com a agressão por armas biológicas, fato que justifica a ênfase dada à organização de uma vigilância global para as doenças emergentes e reemergentes (Kadlec, 1997; Lederberg, 1996). Os recentes acontecimentos na esfera das relações internacionais elevaram esta questão ao primeiro plano das preocupações da Organização Mundial da Saúde.

Entre as doenças infecciosas emergentes de maior relevância em saúde pública, podemos apontar algumas relacionadas ao desenvolvimento tecnológico, como as in- 
fecções por microorganismos resistentes a antimicrobianos, problema em parte decorrente do uso inadequado desses medicamentos, refletindo até certo ponto a qualidade da assistência médica, com sérios reflexos na morbimortalidade hospitalar e no custo dos serviços (Davies e Webb, 1988).

Infecções transmitidas por alimentos têm aumentado significativamente sua importância à medida que é ampliado o uso de alimentos industrializados (Tauxe, 1997). Alimentos de origem animal apresentam um risco adicional, pois podem serveículo de transmissão de microorganismos resistentes a antimicrobianos quando originários de rebanhos alimentados com ração adicionada de antibióticos de largo espectro (Holmberg et al., 1984).

Tecnologias recém-introduzidas em produtos de amplo consumo podem dar origem a epidemias cuja etiologia torna-se de difícil identificação. Foi o caso da epidemia da síndrome do choque tóxico entre mulheres em idade fértil, ocorrida nos EUA no final dos anos 70, induzida pelo uso de absorventes internos recentemente introduzidos no mercado (Davis e Vergeront, 1982).

Em 1986, foi identificada na Inglaterra uma epidemia de doença neurológica desconhecida, acometendo rebanhos de gado em diversas regiões do país. Ela recebeu a denominação de encefalite espongiforme bovina ou doença da "vaca louca", doença associada a um agente infeccioso ainda não descrito, o príons. As investigações dessa epidemia verificaram que a contaminação desses rebanhos estava associada à introdução na ração desses animais de proteína de carneiros, cujos rebanhos, na Inglaterra, sofriam endemicamente de doença neurológica semelhante. Na década de 90, surgiram na Europa casos humanos de uma doença neurológica semelhante à síndrome de Creutzfeldt-Jacob, aparentemente ligados ao consumo de carne bovina originária de rebanhos atingidos pela referida encefalite bovina (Nathanson et al., 1997). As repercussões desta questão em termos de saúde pública e de relações econômicas internacionais têm sido amplamente discutidas na imprensa.
A dengue foi a doença que provavelmente alcançou, em todo o mundo, a maior expansão nos últimos quinze anos, atingindo de forma epidêmica praticamente todos os continentes. Esse comportamento reflete não só a grande intensificação do intercâmbio internacional que tem facilitado a disseminação do seu vetor, como também modificações do ambiente, principalmente o urbano, favorecendo sua rápida multiplicação, tornando difícil o controle da transmissão e criando condições potenciais para extensas epidemias da forma hemorrágica da doença (Gubler, 1998).

Outro exemplo da importância do intercâmbio internacional no estabelecimento de condições propícias ao surgimento de infecções emergentes foi a introdução no continente norte-americano do vírus da encefalite do oeste do Nilo, endêmico no norte da África, ocasionando epidemia com vários óbitos na cidade de Nova York, em 1999. Hoje esse vírus encontra-se em processo de rápida disseminação em todo o continente norte-americano (Nash et al., 2001).

A adaptação de um microorganismo ao homem é outra forma de introdução de uma nova doença. Foi o caso do vírus da imunodeficiência humana (HIV), provavelmente originário de um retrovírus do macaco adaptado ao homem, produzindo epidemia que teve início nos anos 80 e já atingiu todos os continentes, com sérias repercussões em saúde pública, especialmente no continente africano (Faucci, 1999).

A modificação de comportamento de um agente conhecido também pode criar riscos significativos para a saúde da população. Um exemplo é a febre purpúrica brasileira, causada por um clone do Haemophilus aegyptious, bactéria conhecida desde o final do século XIX, e associada exclusivamente à conjuntivite purulenta, uma infecção autolimitada. No entanto, por motivos ainda não perfeitamente conhecidos, essa bactéria passou a apresentar uma forma clínica grave com infecção sistêmica e elevada letalidade a partir de meados dos anos 80. Essa doença foi registrada em alguns estados brasileiros tanto na forma de casos esporádicos 
como em epidemias, e seu potencial de expansão ainda está por ser estabelecido (Harrison et al., 1989).

Os fatores associados à reemergência de doenças infecciosas são muito semelhantes àqueles apontados como associados às doenças infecciosas emergentes. O recrudescimento da tuberculose em várias regiões do mundo, a partir da segunda metade dos anos 80, que atingiu inclusive países industrializados, é um bom exemplo. Neste caso, estiveram envolvidos a desestruturação dos serviços de saúde; o aparecimento de cepas multirresistentes de $M$. tuberculosis, fato em parte relacionado ao uso inadequado dos esquemas terapêuticos; a ampliação por motivos políticos e econômicos dos processos migratórios, levando indivíduos originários de países de elevada prevalência a se dirigirem a países industrializados; e, por fim, a co-infecção causada pela M. tuberculosis e pelo HIV. Alguns autores atribuem a esse último fator o papel mais relevante no incremento das taxas de tuberculose nos últimos anos (Raviglione et al., 1993; Snider e Hoper, 1992).

O reaparecimento da difteria nos países que formavam a antiga União Soviética, na forma de extensa epidemia, com dezenas de milhares de casos e milhares de óbitos, nos primeiros anos da década de 90, após várias décadas de controle da doença, ainda que não esteja perfeitamente explicado, se aceita entre os fatores envolvidos: 1) o aumento de crianças suscetíveis em função da diminuição da eficiência do programa de vacinação; 2) o aumento de suscetíveis entre adultos por perda da imunidade e ausência de programas de imunização para faixas etárias mais altas; 3 ) a piora nas condições socioeconômicas; 4) e o aumento de fluxos migratórios (Vitek e Wharton, 1998).

Outra doença passível de prevenção por vacinação que tem apresentado sinais de recrudescimento é a coqueluche, mesmoem países que utilizaram extensivamente a vacina, como Holanda, Canadá e Austrália. Uma possível explicação para o fato seria a ocorrência de uma progressiva seleção de cepas antigenicamente distintas daquelas utilizadas na produção de vacinas, criando condições para que a doença mantenha-se endêmica a despeito de elevadas coberturas de vacinação (De Melker et al., 1997).

Em função dos bons resultados do Plano de Erradicação, a poliomielite não foi registrada nas Américas desde 1991. No entanto, a doença ressurgiu em sua forma epidêmica em meados do ano 2000, na República Dominicana e Haiti, associada à circulação de uma cepa de poliovírus tipo 1 derivada do vírus vacinal. Esse vírus vacinal que recuperou sua capacidade de causar paralisias transmite-se pessoa a pessoa e não é biologicamente distinguível do vírus selvagem. Cabe salientar, porém, que as crianças atingidas nessa epidemia não haviam sido adequadamente vacinadas (CDC, 2001).

Para a melhor compreensão do que vem a ser a reemergência de doenças infecciosas, é importante delimitar precisamente os conceitos de erradicação, eliminação e controle de doenças. De modo sucinto, pode-se dizer que a erradicação de uma doença transmissível implica a extinção, em todo o globo, por métodos artificiais, do agente etiológico da doença objeto do programa, sendo por conseqüência impossível sua reintrodução e totalmente desnecessária a manutenção de quaisquer medidas de vigilância, prevenção ou controle. Cumpre salientar que esse objetivo raramente é passível de ser atingido, sendo a erradicação da varíola uma exceção e não a regra em saúde pública (Last, 2001).

Uma alternativa próxima à erradicação, porém mais viável, é a eliminação de uma doença, que se obtém pela cessação da sua transmissão em extensa área geográfica, persistindo, no entanto, o risco de sua reintrodução, seja por falha na utilização dos instrumentos de controle, seja pela modificação do comportamento da doença. Por outro lado, no controle aceita-se a convivência com a doença, porém em níveis de transmissão bem baixos, de forma que ela deixe de ser um problema de saúde pública. Tanto na eliminação como no controle de doenças, é indispensável manter de modo regular e contínuo as medidas de intervenção pertinentes, além da vigilân- 
cia, instrumento que permite a análise contínua do comportamento das doenças na população, com fundamento no conhecimento científico disponível, com o objetivo de estabelecer as bases técnicas das medidas de controle (Evans, 1985).

Das propostas recentes de erradicação, podemos apontar entre as mais importantes a da poliomielite, que se encontra num estágio muito avançado, e a do sarampo, que tem sofrido alguns reveses, como a epidemia que atingiu o Brasil e outros países latino-americanos em 1997 e 1998. A despeito de existirem evidências de sérios obstáculos para que se atinja a erradicação do sarampo, os resultados alcançados em termos de diminuição da morbimortalidade podem ser considerados excelentes. Ao compararmos as eras pré e pós-introdução da vacinação, verificaremos uma diminuição, em todo o globo, de $78 \%$ na morbidade e de $88 \%$ na mortalidade causada por essa doença (CDC, 1998).

Apesar de resultados favoráveis desses dois programas, não há dúvida que as dificuldades para atingirmos a erradicação não serão pequenas. Existem hoje vários epidemiologistas de inegável experiência, entre eles Henderson, um dos coordenadores da Campanha de Erradicação da varíola, que aconselham uma rediscussão dessas propostas (Gouder, 1998; Henderson, 1992; Taylor et al., 1997). A complexidade do tema e a ampla gama de argumentos não nos permitem tocar em profundidade esta questão, mas de um modo geral o que esses autores propõem é a reformulação dos planos de erradicação, redirecionando-os para os seguintes objetivos: 1) fortalecer as redes básicas de saúde, que trabalhariam focalizando prioridades locais ou regionais; 2) criar condições para o maior envolvimento de organizações não-governamentais nos programas de controle/eliminação/erradicação de doenças; 3 ) fortalecer a pesquisa e a vigilância nos países em desenvolvimento com vistas a fundamentar tecnicamente e aprimorar continuamente os programas de controle de doenças nessas regiões.

A atual situação de instabilidade internacional, aumentando o risco de utilização de armas biológicas e apontando como possibilidade o uso, com tal finalidade, do vírus da varíola, possivelmente resultará numa discussão mais aprofundada dos planos de erradicação de doenças infecciosas. Editorial publicado pela revista The Lancet, em 1999, já alertava para tal problema, salientando que, em decorrência da certificação da erradicação da varíola, em 1980, foi suspensa, desde aquela época, a vacinação da população civil de todos os países, estimando-se que atualmente somente $20 \%$ das pessoas, em todo o mundo, apresentam imunidade contra a varíola, doença que pode matar até $35 \%$ dos indivíduos atingidos. Salienta também que nenhum país atualmente possui estoque de vacinas suficiente para enfrentar uma epidemia de grande proporção.

Esses fatos tornam atual a frase escrita por Rene Dubos, em 1965, quando tudo indicava que a campanha de erradicação da malária não atingiria seus objetivos: “Public health administrators, like social planners, have to compromise with the limitations of human nature. For this reason, and many others, eradication programs will eventually become a curiosity item on library shelves, just as have all social utopias".

\section{DOENCAS INFECCIOSAS EMERGENTES E REEMERGENTES: UM NOVO PROBLEMA OU UMA NOVA ABORDAGEM EM SAÚDE PÚBLICA}

Em termos estritos, devemos assinalar que as doenças infecciosas, particularmente aquelas que alcançaram maior relevância em saúde pública, com freqüência apresentaram caráter emergente, não constituindo este aspecto um fenômeno novo. Basta lembrar que em diferentes momentos da história elas surgiram de forma inesperada, determinando impacto não só na economia, mas também na estrutura demo- 
gráfica dos povos; é o caso da epidemia de peste na Idade Média, com graves repercussões no continente europeu, e da "gripe espanhola" de 1918 que, de acordo com estimativas, dizimou cerca de $1 \%$ da população humana (Lederberg, 1997 ; McNeill, 1989).

A título de curiosidade, cabe assinalar que nem sempre a emergência de um novo agente infeccioso mostrou-se deletéria ao homem. Exemplo interessante ocorreu em nosso país, no início do século XX. A varíola major era até então a única forma da doença existente no Brasil, tendo sido responsável, em 1907, por terrível epidemia na cidade do Rio de Janeiro, levando ao óbito cerca de $1 \%$ da população (Thibau Jr., 1959). No entanto, nessa mesma época, foi introduzido no Brasil o vírus da varíola minor, provavelmente originária da África. Por sua maior infecciosidade e, provavelmente, por outros determinantes menos conhecidos, conseguiu em poucos anos deslocar o vírus da varíola major do território nacional, tornando essa doença, até então de elevada letalidade, num problema de menor importância em saúde pública (Ribas, 1910).

$\mathrm{Na}$ verdade a denominação - doenças infecciosas emergentes e reemergentes -aplicada a partir dos anos 90 reflete a busca de uma nova abordagem, na tentativa de identificaros instrumentos necessários para fundamentar e implementar novas estratégias de controle de doenças, num mundo onde a introdução de novos fatores de risco e mudanças das características dos grupos a eles expostos ocorrem com extrema rapidez.

Para responder a esse desafio é necessário, por um lado, que a sociedade busque a equiidade, pois a miséria ainda apresenta vínculo importante com as doenças infecciosas, e por outro a organização de um sistema de saúde com grau apreciável de auto-sustentação, ou seja, com capacidade de responder a problemas prioritários e emergentes. Isso somente será possível com serviços de saúde estruturados e planejados de maneira a incorporarem, de forma ágil, novos conhecimentos e tecnologias indispensáveis à elaboração, implementação, avaliação e atualização contínua de estratégias de controle de doenças.

Deverá também fortalecer a pesquisa não só no âmbito acadêmico, mas no interior do próprio sistema de saúde. Vale salientar que tanto a pesquisa acadêmica como aquela que deve ser atribuída aos institutos de pesquisa vinculados ao sistema de saúde possuem características peculiares e devem desempenhar papéis complementares, merecendo, portanto, políticas bemdefinidas que fortaleçam seus vínculos de forma a garantir o desempenho desejado. Tal objetivo pode ser alcançado por meio de sistemas de financiamento e pela avaliação e controle social das instituições envolvidas.

Um instrumento fundamental para o bom desempenho do sistema de saúde no controle das doenças emergentes e reemergentes é a vigilância com forte apoio laboratorial, o que pressupõe a existência de equipes muito bem treinadas em investigações de surtos epidêmicos e no desenvolvimento de pesquisas complementares, assim como na análise sistemática do comportamento dessas doenças, com fundamento no conhecimento científico, com a finalidade de atualizar continuamente as bases técnicas que subsidiam as estratégias de controle.

A vigilância no sentido de inteligência epidemiológica, conceito desenvolvido a partir dos anos 50 (Langmuir e Andrews, 1952; Langmuir, 1971; Langmuir, 1976), para ser aplicada de forma abrangente, deve ser entendida como o elo entre os serviços de saúde e a pesquisa, ou seja, um instrumento de identificação de lacunas no conhecimento, de indução da pesquisa e voltado à rápida incorporação pelos serviços de saúde do conhecimento produzido, garantindo a contínua atualização das estratégias. O sucesso na utilização desse sistema de indução, produção e incorporação do conhecimento produzido constitui fator indispensável não só para a eficiência no controle de doenças mas para o bom desempenho do sistema de saúde na resposta às necessidade da sociedade. 


\section{BIBLIOGRAFIA}

ALTEKRUSE, S. F.; COHEN, M. L.; SWERDLOW, D. L. "Emerging Foodborne Diseases", in Emerg. Infect. Dis., 3(3), 1997, pp. 285-93.

ARMELAGOS, G. J. "The Viral Superhighway", in The Sciences, Jan./Febr./1998, pp. 24-9.

BEAGLEHOLE, R. e BONITA, R. Public Health at the Crossroads. Cambridge, Cambridge University Press, 1998.

BOBADILLA, J. L.; FRENK, J.; LOZANO, R.; FREJKA, T.; STERN, C. "The Epidemiologic Transition and Health Priorities", in Disease Control Priorities in Developing Countries. Oxford, Oxford University Press, 1993, pp. 161-87.

CDC - CENTERS FOR DISEASE CONTROL AND PREVENTION. Addressing Emerging Infectious Disease Threats. A Prevention Strategies for the United States. 1994.

. "Advances in Global Measles Control and Elimination: Summary of the 1997 International Meeting", in MMWR - Recommendations and Reports, 47 (RR-1 1), 1998, pp. 1-23.

. "Public Health Dispatch: Outbreak of Polimyelitis - Dominican Republic and Haiti, 2000 - 2001", in MMWR, 50(39), 2001, pp. 855-66.

DAVIES, J.; WEBB, V. "Antibiotic Resistence in Bacteria", in R. M. Krause, Emerging Infections: Biomedical Research Reports. New York, Academic Press, 1988, pp. 239-73.

DAVIS, V. P.; VERGERONT, J. M. "The Effect of Publicity on the Reporting of Toxic-shock Syndrome in Wisconsin", in J. Infect. Dis., 145, 1982, pp. 449-57.

DE MELKER, H. E.; CONYN-VAN SPAENDOCK, M. A. E.; RÜMKE, H. C.; VAN WIJNGAARDEN, J. K,; MOOI, F. R.;

SCHELLEKENS, J. F. P. "Pertussis in the Netherlands: na Outbreak Despite High Levels of Immunization with Whole Cell Vaccine", in Emerg. Infec. Dis., 3, 1997, pp. 175-8.

DUBOS, R. Man Adapting. New Haven, Yale University Press, 1965.

EDITORIAL. "Is Smallpox History?", in Lancet, 353(9164), 1999.

EVANS, A. S. “The Eradication of Communicable Diseases: Myth or Reality?", in Amer. J. Epidemiol., 122, 1985, pp. 199-207.

FAUCCI, A. S. "The Aids Epidemic 1999", in N. Engl. J. Med., 341 (14), 1999, pp. 1.047-50.

FIDLER, J. D. "Globalization, International Law, and Emerging Infectious Diseases", in Emerg. Infec. Dis., 2(2), 1996, pp. 77-84.

FRENK, J.; BOBADILLA, J. L.; SEPULVEDA, J.; CERVANTES, M. L. “Health Transition in Middle-income Countries: New Challenges for Health Care", in Health Policy and Planning, 4(1), 1998, pp. 29-39.

GOUDER, C. "The Progress of the Polio Eradication Iniciative: What Prospects for Eradicating Measles?", in Health Policy Planning, 13(3), 1998, pp. 212-33.

GUBLER, D. J. "The Global Pandemic of Dengue/Dengue Haemorrhagic Fever: Current Status and Prospects for the Future", in Ann. Acad. Med. Singapore, 27, 1998, pp. 227-34.

HARRISON, L. H.; BROOME, C. V.; AJELLO G. et al. "Report of Symposium. Brazilian Purpuric Fever", in Pediat. Infect. Dis. J., 8 (4), 1989, pp. 237-49.

HENDERSON, D. A. "Strategies for the Twenty-first Century - Control or Eradication?", in D. H. Walker (ed.), Global Infectious Diseases. Prevention, Control, and Eradication. New York, Springer-Verlag, 1992.

HOLMBERG, S. D.; OSTHERHOLM, M. T.; SENGER, K. A.; COHEN, M. L. “Drug-resistent Salmonella from Animals Fed Antimicrobials", in N. Engl. J. Med., 311, 1984, pp. 617-22.

KADLEC, R. P.; ZELIKOFF, A. P.; VRTIS, A. M. "Biological Weapons Control. Prospects and Implications for the Future", in JAMA, 278(5), 1997, pp. 351-6.

LANGMUIR, A. D.; ANDREWS, J. M. “Biological Warfare Defence. 2 - The Epidemic Inteligence Service of the Communicable Disease Center", in Amer. J. Publ. Hlth., 42, 1952, pp. 235-8.

LANGMUIR, A. D. "Evolution of the Concept of Surveillance in the United States", in Proc. Roy. Soc. Med., 64, 1971, pp. 681-4.

"Willian Farr: Founder of Modern Concepts of Surveillance", Int. J. Epidem., 5, 1976, pp. 13-8. 
LAST, J. M. A Dictionary of Epidemiology. New York, Oxford University Press, 2001.

LEDERBERG, J.; SHOPE, R. Emerging Infections: Microbial Threats to Health in United States. Washington, National Academy Press, 1992.

LEDERBERG, J. "Infectious Diseases - a Threat to Global Health and Security", in JAMA, 276(5), 1996, pp. 417-9. . "Infectious Diseases as a na Evolutionary Paradigm", in Emerg. Infect. Dis., 3(4), 1997, pp. 417-23.

MCNEILL, W. H. Plagues and Peoples. New York, Anchor Books/Doubleday, 1989.

MORSE S. S. "Factors in the Emergence of Infectious Diseases", in Emerg. Infect. Dis., 1 (1), 1995, pp. 7-15.

MORSE, S. S.; HUGHES, J. M. "Developing and Integrates Epidemiologic Approach to Emerging Infectious Diseases", in Epidemiol. Rev., 18(1), 1996, pp. 1-3.

NASH, D.; MOSTASHARI, F.; FINE, A.; MILLER, J. et al. "Outbreak of West Nile Virus, New York City Area, 1999", in N. Engl. J. Med., 344, 2001, pp. 1.807-14.

NATHANSON, N.; WILESMITH, J.; GRIOT, C. "Bovine Spongiform Encephalitis (BSE): Causes and Consequences of a Commun Source Epidemic", in Amer. J. Epidemiol., 145(11), 1997, pp. 959-69.

POWLES, J. "Changes in Disease Patterns and Related Social Trends", in Soc. Sci. Med., 35, 1992, pp. 377-87.

RAVIGLIONE, M. C. et al. "Secular Trends of Tuberculosis in Western Europe", in Bull. WHO, 71 (3/4), 1993, pp.

297-306.

RIBAS, E. "Alastrim, Amaas ou Milk-pox", in Rev. Med. São Paulo, 1910, pp. 323-39.

SATCHER, D. "Emerging Infectious: Getting Ahead of the Curve", in Emerg. Infec. Dis., 1 (1), 1995, pp. 1-6.

SNIDER, D. E.; ROPER, W. L. “The New Tuberculosis", in N. Engl. J. Med., 326, 1992, pp. 703-5.

TAUXE, R. V. “Emerging Foodborne: Na Evolving Public Health Challenge”, in Emerg. Infec. Dis., 3(4), 1997, pp.

425-34.

TAYLOR, C. E.; CUTTS, F.; TAYLOR, M. E. "Ethical Dilemmas Incurrent Planning for Polio Eradication”, in Am. J. Publ. Health, 87, 1997, pp. 922-5.

THIBAU JR., E. "A Mortalidade por Dez Doenças no Rio de Janeiro, em Meio Século", in Rev. Brasil. Med., 16, 1959, pp. 503-25.

VITEK, C. R.; WHARTON, M. "Dipheteria in the Former Soviet Union: Reemergence of a Pandemic Disease", in Emerg. Infec. Dis., 4(4), 1998.

WORLD HEALTH ORGANIZATION. "Leading Causes of Mortality and Burden of Disease Estimates for 1998”, in World Health Report, 1999. 